\title{
Differences between Arkansas and the United States in Prevalence of Risk Factors Explain Variations in Ischemic Heart Disease Mortality Rates among Pre-Medicare (45-64) and Medicare (65-84) Age Groups
}

\author{
Robert Delongchamp 1,2*, Abby Holt ${ }^{2}$, M. F. Faramawi ${ }^{1}$, Appathurai Balamurugan 1,2, Gordon Reeve ${ }^{2}$, \\ Namvar Zohoori ${ }^{1,2}$, Joseph Bates ${ }^{1,2}$ \\ 1 University of Arkeansas for Medical Sciences (UAMS), U.S.A. \\ 2 Arkansas Department of Health, U.S.A.
}

*Corresponding Author: rdelongchamp@uams.edu

Citation: Delongchamp, R., Holt, A., Faramawi, M. F., Balamurugan, A., Reeve, G., Zohoori, N. and Bates, J. (2019). Differences between Arkansas and the United States in Prevalence of Risk Factors Explain Variations in Ischemic Heart Disease Mortality Rates among Pre-Medicare (45-64) and Medicare (65-84) Age Groups. European Journal of Environment and Public Health, 3(1), em0024. https://doi.org/10.29333/ejeph/5838

Published: July 11, 2019

\begin{abstract}
Arkansas (AR) consistently has higher ischemic heart disease (IHD) death rates than the US, which is believed to be due to a higher prevalence in AR of major, modifiable risk factors. We examined the difference in IHD death rates between AR and the US as consequences of differences in the prevalence of nine risk factors between pre-Medicare age group (45-64) and Medicare age group (65-84). We modeled IHD deaths attributable to differential prevalence between AR and the US using mortality data and prevalence data from AR and US for years 2000-2010, and relative risk measures obtained from the INTERHEART and Atherosclerosis Risk in Communities studies. From 2000-2010, our study showed that if we were to reduce the prevalence of significant risk factors to US levels, we would reduce AR IHD deaths by $26.6 \%$ in the pre-Medicare age group and $15.9 \%$ in the Medicare age group. Most of the increased mortality was explained by higher prevalence of smoking and hypertension in AR. Other socioeconomic factors that contributed to an increased risk of poor health outcomes were education, income, and the lack of health insurance; with AR having worse outcomes than the US for the pre-Medicare age group. The importance of risk factors depended on race, sex, and age. The excess mortality in AR relative to the US for the two age groups can largely be explained by prevalence differences in smoking, hypertension, cholesterol, education and income.
\end{abstract}

Keywords: risk factors, mortality, ischemic heart disease

\section{INTRODUCTION}

Although death rates from heart disease in the United States (US) and Arkansas (AR) have declined rapidly since the 1970s, the burden remains high (Centers for Disease Control and Prevention, 2013; Gillespie et al., 2013; Go et al., 2014). In 2013, heart disease was the leading cause of death in the US and AR with ischemic heart disease (IHD) contributing the majority of these deaths (Centers for Disease Control and Prevention, 2014). AR has substantially higher IHD death rates than the US (Centers for Disease Control and Prevention, 2014).

Major modifiable risk factors for heart disease have been extensively studied and elucidated. However, their contribution to the excess mortality of high-burden states have not. These risk factors include tobacco use, physical 
inactivity, poor diet, diabetes, obesity, hypertension, and dyslipidemia; managing these risks can prevent the onset of IHD and premature death (American Heart Association, 2018; Go et al., 2014). In a recent study by Patel and coworkers, several of these major preventable risks combined accounted for half of the cardiovascular disease deaths in US adults aged 45-79 (Patel et al., 2015). This study suggests that nearly $10 \%$ of the nation's cardiovascular disease deaths would be prevented if risk factors were reduced to the levels in the lowest risk states. This is the only national cardiovascular study published that we know of that measured a decrease in cardiovascular mortality if all states were to reduce modifiable risks to a specified target.

In addition to public health efforts focused on reductions in modifiable risk factors, access to healthcare could be important in reducing IHD mortality (Cutler and Meara, 2004). Arkansans in the pre-Medicare age group (age 45-64) not only have higher IHD death rates than the nation, but many have also historically lacked healthcare insurance as compared to the nation. A recent study by Case and Deaton found a marked increase in all-cause mortality in middle-aged, white men and women in the US between 1999 and 2013, reversing decades of progress in mortality (Case and Deaton, 2015). The percent of the population under the age of 65 without healthcare insurance in AR significantly exceeded the percent in the US in 2013 [19.1\% (90\% confidence interval [CD]: 18.419.8) versus 16.5\% (90\% CI: 16.3-16.5), respectively (US Department of Health \& Human Services, 2015), making this sub-population particularly vulnerable.

We investigated the contribution of the differences, between Arkansas and US, in the prevalence of major, modifiable risk factors, including health insurance, in pre-Medicare (45-64 years of age) and Medicare (65-84 years of age) age groups, to explore the effects that such reductions could have on the excess IHD mortality in Arkansas.

\section{METHODS}

The prevalence for each, modifiable, risk factor was estimated from the Behavioral Risk Factor Surveillance System (BRFSS) (Centers for Disease Control and Prevention, 2018a). IHD mortality rates were obtained from CDC Wonder, and population attributable fractions were calculated using the BRFSS prevalence estimates and published relative risks (Anand et al., 2008; Fowler-Brown et al., 2007; Lynch et al., 1996; Qureshi et al., 2003; Rasmussen et al., 2006; Tonne et al., 2005). The details are described in sections labeled: Mortality, Prevalence and Adjustment.

For major modifiable risk factors, AR IHD mortality was adjusted by a population attributable fraction that assumed AR prevalence was reduced to US levels. Mortality adjustments were computed for the years, 2000 to 2010. IHD mortality rates were obtained for the US and AR, and prevalence of each risk factor was estimated for each year for both the US and AR. Within each year, we computed age-standardized mortality rates and agestandardized prevalence rates for eight demographic groups representing combinations of age (Older and Young), race (Black and White), sex (Female and Male). Older represents individuals in the Medicare age group and young represents adults between 45-64 years of age. Each group is labeled using a three letter code: Y means younger (age 45-64), O means older (65-84), W means non-Hispanic white, B means non-Hispanic black.

\section{Mortality}

Mortality rates for IHD (International Classification of Diseases - revision 10 codes I20-I25) in AR and in the US were obtained from the CDC Wonder compressed mortality files from 2000 to 2010 (Centers for Disease Control and Prevention, 2014). In Arkansas, a total of 11,272 IHD deaths among the 45-64 age group and 26,430 IHD deaths among the 65-84 age group were included in the study. In the US, a total of 716,405 IHD deaths among the 45-64 age group and 2,097,502 IHD deaths among the 65-84 age group were included. We downloaded age-specific IHD mortality rates for five-year age intervals and computed annual age-standardized rates in AR and the US for each of eight race-sex-age groups. Rates were adjusted in 5-year age groups to the 2000 US standard million.

\section{Prevalence}

Survey results from the BRFSS were used to assess the prevalence of nine risk factors in the eight demographic groups in the US and AR (Centers for Disease Control and Prevention, 2018a). The annual prevalence of personal health behaviors were estimated for years 2000 to 2010. Included IHD risk factors were the prevalence of cigarette smoking, hypertension awareness, high cholesterol awareness, obesity, physical inactivity, diabetes, income, educational attainment, and health insurance status. The specific definitions of risk factor categories are given in Table 1. Demographic information of sex, age, and race were obtained from BRFSS. All other items were obtained from the core BRFSS survey for all years 2000-2010, with the exception of hypertension, cholesterol awareness and physical inactivity; these items were obtained from rotating core questions asked every other year during 2001, 2003, 2005, 2007, and 2009. Because BRFSS data collection methods change over time, modifications to the 
Table 1. Risk factor categories defined from the CDC Behavioral Risk Factor Surveillance System (BRFSS)

\begin{tabular}{|c|c|}
\hline Risk Factor Categories & BRFSS Definitions \\
\hline Smoking: never, former, current & $\begin{array}{l}\text { Never smoker }=\text { Respondent who reported smoking less than } 100 \text { cigarettes in their lifetime. } \\
\text { Former smoker }=\text { Respondent who reported smoking at least } 100 \text { cigarettes in their lifetime and who did } \\
\text { not smoke at the time of the survey. } \\
\text { Current smoker }=\text { Respondent who reported smoking at least } 100 \text { cigarettes in their lifetime and who } \\
\text { smoked every day or some days at the time of the survey. }\end{array}$ \\
\hline Hyperter & $\begin{array}{l}\text { Respondent who has been told by a doctor, nurse, or other health professional that they have high blood } \\
\text { pressure. }\end{array}$ \\
\hline Cholesterol: no, yes & $\begin{array}{l}\text { Respondent who has been told by a doctor, nurse, or other health professional that their blood cholesterol } \\
\text { is high. }\end{array}$ \\
\hline Obesity: $\mathrm{BMI}<30, \mathrm{BMI} \geq 30$ & Body mass index (BMI) calculated by the CDC from a respondent's reported height and weight. \\
\hline Physical Activity: no, yes & $\begin{array}{l}\text { Respondent who reported they participated in either moderate physical activity defined as } 30 \text { or more } \\
\text { minutes per day for } 5 \text { or more days per week, or vigorous activity for } 20 \text { minutes per day on } 3 \text { or more } \\
\text { days per week. }\end{array}$ \\
\hline Diabetes: no, yes & Respondent who has been told by a doctor that they have diabetes. \\
\hline $\begin{array}{l}\text { Income: } \\
<\$ 15,000 \text { per year, } \geq \$ 15,000\end{array}$ & $\begin{array}{l}\text { Respondent with an annual household income from all sources falling within the following categories: } \\
<\$ 15,000 \text { per year } \\
\$ 15,000 \text { to less than } \$ 25,000 \\
\$ 25,000 \text { to less than } \$ 35,000 \\
\$ 35,000 \text { to less than } \$ 50,000 \\
\$ 50,000 \text { or more }\end{array}$ \\
\hline $\begin{array}{l}\text { Education: }<\text { high school } \\
\text { graduate, } \\
\geq \text { high school graduate }\end{array}$ & $\begin{array}{l}\text { Respondent who reported the highest grade or year of school that they completed; tabulated by the CDC } \\
\text { as: } \\
\text { 1. Did not graduate high school } \\
\text { 2. High school graduate } \\
\text { 3. Attended college or technical school } \\
\text { 4. College or technical school graduate }\end{array}$ \\
\hline Health Insurance Status: no, yes & $\begin{array}{l}\text { Respondent who had any kind of health care coverage, including health insurance, prepaid plans such as } \\
\text { HMO's, or government plans such as Medicare. }\end{array}$ \\
\hline
\end{tabular}

Table 2. Excess relative risk used in population attributable risk calculations by sex and age

\begin{tabular}{|c|c|c|c|c|}
\hline Risk Factor & Males $\geq 65$ & Males 45-64 & Females $\geq 65$ & Females 45-64 \\
\hline Smoking Status ${ }^{(a)}$ (Current + Former) & $1.28+.50$ & $2.42+.70$ & $1.29+.17$ & $3.40+.40$ \\
\hline Hypertension $^{(\mathrm{a})}$ & 1.02 & 1.63 & 1.84 & 3.00 \\
\hline High Cholesterol(a) & 1.02 & 2.63 & 1.65 & 3.85 \\
\hline Obesity(a) & 0.84 & 1.51 & 1.03 & 1.56 \\
\hline Physical Inactivity(a) & 1.61 & 1.25 & 1.85 & 1.67 \\
\hline Diabetes $^{(a)}$ & 1.47 & 1.93 & 2.71 & 4.69 \\
\hline Education(b) $^{(b)}$ & 1.0 & 1.0 & 1.0 & 1.0 \\
\hline Income $(\mathrm{b})$ & 1.0 & 1.0 & 1.0 & 1.0 \\
\hline No Health Insurance ${ }^{(c)}$ & .22 & .22 & .22 & .22 \\
\hline \multicolumn{5}{|l|}{ (a) RR from INTERHEART study (11) } \\
\hline (b) RR set to $2.0(15-18)$ & & & & \\
\hline (c) RR from the Atherosclerosis in Comt & nities Study (12) & & & \\
\hline
\end{tabular}

variable names and methods of collection were assessed and recoded when needed for consistency throughout all years (Centers for Disease Control and Prevention, 2015).

Hypertension and diabetes may be underreported because participants are unaware that they have these conditions. To adjust for this, results from a state-level randomized survey conducted from 2006 to 2008, Arkansas Cardiovascular Health Examination Survey (ARCHES), which collected self-reported and clinical measures, were used (Zohoori et al., 2011). ARCHES methodology was similar to the National Health and Nutrition Examination Survey (NHANES). NHANES, 2007 to 2008, reported that $80.7 \%$ of the respondents who had hypertension were aware of their condition; while $72.6 \%$ of ARCHES respondents were aware of their hypertension. Among respondents who self-reported they had been diagnosed with diabetes, $67.9 \%$ of NHANES respondents were aware of their diagnosis; while $76.7 \%$ of ARCHES respondents were aware of their condition (Centers for Disease Control and Prevention, 2018c; Zohoori et al., 2011).

\section{Adjustment}

The majority of the relative risk measures (smoking, hypertension, obesity, physical inactivity, diabetes) were obtained as odds ratios from the INTERHEART study, a worldwide case-control study of factors associated with acute myocardial infarction, as set out in Table 2 (Anand et al., 2008). Income, educational attainment, and health insurance status were not measured in this study; therefore, the Atherosclerosis Risk in Communities Study (ARIC) was used to determine the RR for the lack of health insurance for myocardial infarction (Table 2) (Fowler-Brown 

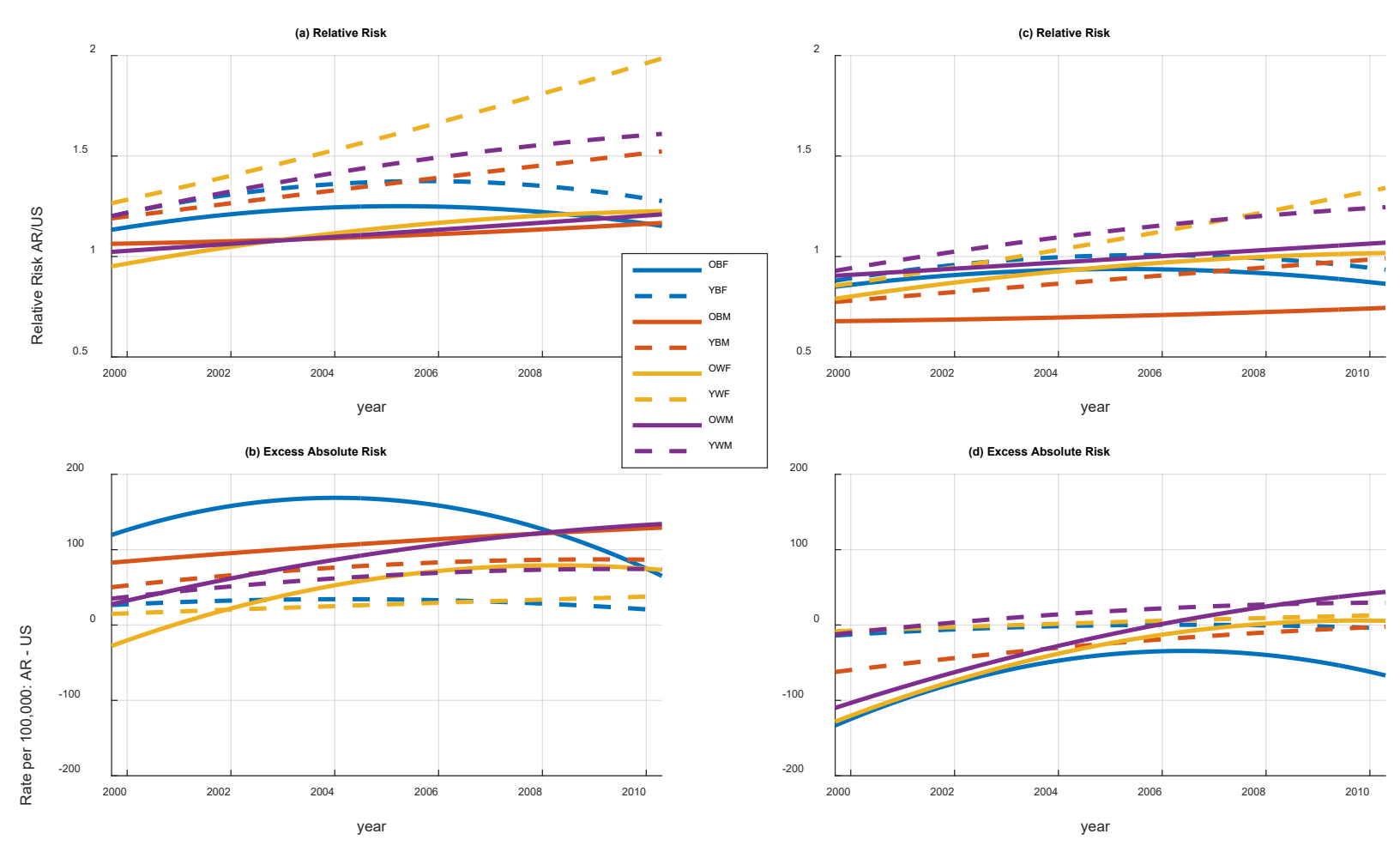

Abbreviations: IHD, ischemic heart disease; AR, Arkansas; US, United States; OBF, older black females (65-84); YBF, younger black females (45-64); OBM, older black males (65-84); YBM, younger black males (45-64); OWF, older white females (65-84); YWF, younger white females (45-64); OWM, older white males (65-84); YWM, younger white males (45-64).

Note that figures (a) and (b) show the mortality rate disparity between AR and the US. Figures (b) and (c) show the decrease in IHD mortality between AR and the US when all nine risk factors in AR are reduced to US levels.

Figure 1. Disparities in age-standardized IHD mortality rates between AR and US. (a) relative risks (b) absolute risks; Disparities in age-standardized mortality after adjusting AR to US prevalence: (c) relative risks and (d) excess absolute risks

et al., 2007). Based on results of several studies that assessed socioeconomic status on cardiovascular disease risks, an RR of 2.0 was assigned to income and educational attainment (Lynch et al., 1996; Qureshi et al., 2003; Rasmussen et al., 2006; Tonne et al., 2005). A generalization of the population attributable fraction was used to compute the anticipated change in the mortality rate with a change in prevalence from $p$ to $q$ :

$$
\theta=\frac{(R-1)(p-q)}{(1+(R-1) p)}
$$

where $R$ is the relative risk in the exposed. Note that the usual definition of population attributable fraction is the case, $q=0$. The adjusted mortality estimate is $\mu(q)=(1-\theta) \mu(p)$. Equation (1) was extended to accommodate multiple exposure levels, such as the joint contribution of smoking and hypertension by cross-classifying the two risk factors (details available from corresponding author).

For $K$ risk factors with respective estimates of the population attributable fraction $\left\{\theta_{k}: k=1, \ldots, K\right\}$, we computed the adjusted mortality as

$$
\left(1-\theta^{*}\right) \mu
$$

where $\theta^{*}=1-\prod_{k=1}^{K}\left(1-\theta_{k}\right)$ is the combined population attributable fraction.

We estimated the population attributable fraction, $\widehat{\theta}$ and its variance from 1,000 bootstrap samples of each survey, 50 states in 11- years (Efron and Tibshirani, 1994). The bootstrap approach provided estimates of variance within domains needed for age-adjusted sex-race categories.

\section{RESULTS}

In all groups, AR had markedly higher IHD mortality than the nation during 2000 through 2010 . To succinctly describe these disparities, we plotted trends in the relative risks (Figure 1a) and the excess absolute risks (Figure 1b). The relative risk and excess absolute risk increased over the years with the exception of black women. Since about 2004, rate disparities among black women declined such that their 2010 disparity was the least among 
Table 3. Rank ${ }^{(a)}$ of significant risk factors as an explanation of the IHD mortality disparity between AR and the US, and population attributable fraction/potential deaths averted in AR

\begin{tabular}{|c|c|c|c|c|c|c|c|c|c|}
\hline $2000-2010$ & OBF $(g)$ & $\mathbf{Y B F}(\mathrm{g})$ & OBM & YBM & OWF & YWF & OWM & YWM & Total \\
\hline Hypertension (c) & 3 & 1 & - & - & - & - & - & - & \\
\hline $\begin{array}{l}\text { Smoking and } \\
\text { Hypertension (c,d) }\end{array}$ & - & - & 2 & 1 & 1 & 1 & 1 & 1 & \\
\hline Cholesterol (b) & - & - & 1 & 2 & - & 2 & - & - & \\
\hline Physical Inactivity (b) & - & - & 4 & - & 4 & 4 & - & - & \\
\hline Diabetes (b) & - & - & - & - & - & - & - & - & \\
\hline$\overline{\text { Obesity (b) }}$ & 4 & 3 & - & - & & 3 & & 2 & \\
\hline Education (e) & 2 & 4 & - & - & 2 & 5 & 2 & 3 & \\
\hline Income (e) & 1 & 2 & 3 & - & 3 & 6 & 3 & 4 & \\
\hline No Health Insurance $^{(\mathrm{f})}$ & - & 5 & & - & - & 7 & & 5 & \\
\hline $\begin{array}{l}\text { Population Attributable } \\
\text { Fraction } \% \\
(95 \% \text { CI })\end{array}$ & $\begin{array}{c}25.0(18.3- \\
31.2)\end{array}$ & $\begin{array}{c}26.8 \\
(21.3-31.9)\end{array}$ & $\begin{array}{c}36.2 \\
(26.4-44.8)\end{array}$ & $\begin{array}{c}\mathbf{3 5 . 0} \\
(24.6-43.9)\end{array}$ & $\begin{array}{c}17.0 \\
(14.5-19.4)\end{array}$ & $\begin{array}{c}\mathbf{3 2 . 5} \\
(23.9-35.9)\end{array}$ & $\begin{array}{c}\mathbf{1 1 . 6} \\
(9.1-14.1)\end{array}$ & $\begin{array}{c}22.7 \\
(19.5-25.7)\end{array}$ & \\
\hline Total IHD Deaths, AR & 1,719 & 667 & 1,521 & 1,309 & 9,618 & 2,550 & 13,572 & 6,716 & 37,672 \\
\hline $\begin{array}{l}\text { Potential Deaths } \\
\text { Averted, AR }\end{array}$ & 430 & 179 & 551 & 458 & 1,635 & 829 & 1,574 & 1,525 & 7,180 \\
\hline
\end{tabular}

Note that empty cells (-) were not ranked because AR prevalence was not significantly greater than the US. Abbreviations: 95\% CI, 95\% confidence interval; IHD, ischemic heart disease; OBF, older black females (65-84); YBF, younger black females (45-64); OBM, older black males (65-84); YBM, younger black males (45-64); OWF, older white females (65-84); YWF, younger white females (45-64); OWM, older white males (65-84); YWM, younger white males (45-64)

(a) Ranking ordered by the magnitude of the statistically significant PAF

(b) RR from the INTERHEART study (11)

(c) Adjusted using data from the Arkansas Cardiovascular Health Examination Survey (ARCHES), 2006 to 2008 (13)

(d) Joint effect of smoking and hypertension

(e) RR set to $2.0(15-18)$

(f) RR from the Atherosclerosis Risk Communities Study (12)

(g) Smoking was not included for OBF, YBF because smoking rates in AR were lower than the US

the race-sex groups. None-the-less, rates in all groups differed significantly from national rates. Further, the relative risks in the pre-Medicare group (YWM, YWF, YBM, YBF) were higher as compared with those in the Medicare group (OWM, OWF, OBM, OBF), Figure 1a.

Conceptually, disparities between AR and US (Figure 1a, 1b) arose from differences in the prevalence of modifiable factors. We evaluated the potential role of the prevalence of nine major, modifiable risk factors for IHD by computing a population attributable fraction (PAF) associated with a change in prevalence from the prevalence that was observed in AR to the prevalence that was observed in the US. Table 3 ranks risk factors for which the PAF was statistically significant. Smoking and hypertension were the major contributors. It is important to note that a disparity in socioeconomic status (i.e., education and income) contributed to IHD mortality differences between AR and the US for most race, sex, and age groups; younger black males (YBM) being the exception, Table 3. Obesity and no health insurance were important in the 45-64 age groups, but not in the 6584 age groups. Diabetes did not contribute to the excess primarily because ARCHES adjusted prevalence was lower in AR than the corresponding US prevalence. Note that the order of the risk factor is a function of the difference between the prevalence in AR and the US, in addition to the excess relative risk in Table 2.

Table 3 also reports the combined PAF of the significant risk factors. Adjusting the relative risk (Figure 1c) or excess absolute risk (Figure 1d) by the PAF associated with these risk factors explained most of the disparity between AR and US IHD mortality rates. Over the period studied, 2000-2010, the greatest IHD mortality difference between AR and the US was in 2010. Table 4 elaborates the 2010 excess absolute risks (EAR) and relative risks (RR) depicted in Figure 1 by reporting 95\% confidence intervals. In 2010, the observed RR and observed EAR were elevated for all groups except OBF, and after the PAF adjustment the disparities were largely removed except for YWF, YWM, and OWM. Older black males (OBM) showed a significant decreasing trend in Table 4.

During the period 2000 to 2010, AR had 11,242 IHD deaths in the 45-64 age group and 26,430 IHD deaths in the 65-84 groups. Applying the PAF estimates in Table 3 to these deaths suggests that $26.6 \%$ of the deaths in the 45-64 groups (2,990 deaths) and 15.9\% of deaths in the 65-84 age group (4,190 deaths) can be attributed to disparities between AR and the US in the prevalence of modifiable risk factors.

\section{DISCUSSION}

This study shows that if Arkansans had the same level of risk factors as the US national average, there would have potentially been $26.6 \%$ fewer deaths from IHD in the 45-64 age group and 15.9\% fewer deaths in the 65-84 
Table 4. 2010 estimates and 95\% confidence bounds of the relative risk, (RR), and excess absolute risk per 100,000, (EAR)

\begin{tabular}{ccccc}
\hline \multicolumn{1}{c}{ Code } & RR $(95 \%$ CI $)$ & RR $^{(a)}(95 \%$ CI $)$ & EAR $(95 \%$ CI $)$ & EAR $($ a) $(95 \%$ CI $)$ \\
\hline OBF & $1.17(1.00-1.36)$ & $0.87(0.73-1.04)$ & $77.8(-6.4-162.1)$ & $-58.8(-131.6-13.9)$ \\
\hline YBF & $1.46(1.18-1.81)$ & $1.07(0.85-1.34)$ & $33.9(10.9-56.9)$ & $5.0(-12.8-22.6)$ \\
\hline OBM & $1.18(1.03-1.35)$ & $0.75(0.62-0.92)$ & $142.5(16.9-268.0)$ & $-198.1(-317.9--78.2)$ \\
\hline YBM & $1.47(1.35-1.60)$ & $0.95(0.80-1.13)$ & $78.2(57.7-98.8)$ & $-7.6(-35.0-19.8)$ \\
\hline OWF & $1.23(1.18-1.29)$ & $1.02(0.97-1.08)$ & $76.8(59.2-94.4)$ & $7.9(-10.3-26.1)$ \\
\hline YWF & $2.05(1.85-2.26)$ & $1.38(1.23-1.55)$ & $40.8(32.9-48.6)$ & $14.9(8.8-20.9)$ \\
\hline OWM & $1.22(1.15-1.30)$ & $1.08(1.01-1.15)$ & $142.1(93.9-190.3)$ & $50.4(2.9-97.9)$ \\
\hline YWM & $1.57(1.48-1.66)$ & $1.21(1.13-1.30)$ & $69.9(58.6-81.1)$ & $26.2(15.5-36.8)$ \\
\hline
\end{tabular}

Abbreviations: 95\% CI, 95\% confidence interval; RR, relative risk; EAR, excess absolute risk; OBF, older black females (65-84); YBF, younger black females (45-64); OBM, older black males (65-84); YBM, younger black males (45-64); OWF, older white females (65-84); YWF, younger white females (45-64); OWM, older white males (65-84); YWM, younger white males (45-64)

(a) AR rates adjusted to expected rates if risk factor prevalence were reduced to US levels

age group during the period 2000 to 2010 . The total number of deaths averted from the IHD would have been 7,180 and almost 3,000 of these would have been in the 45-64 age group; an age group representing a significant proportion of the workforce and those with parental responsibilities. The modifiable risks evaluated included cigarette smoking, obesity, hypertension, high blood cholesterol, diabetes, physical inactivity, education attainment, income level, and health insurance access. The modeling of the IHD mortality in this study accounted for the attributable risk from differential prevalence between AR and US after adjusting for confounders such as age, race, and gender. This methodology focuses on modifiable factors that have been reduced in other states relative to AR and provides a ranking of risk factors by their potential to reduce IHD rates in AR. Smoking and hypertension explained a large portion of the disparity between the AR and US IHD death rates, which implies that other states have reduced smoking and hypertension rates substantially more than AR. Another national study found the greatest reduction in cardiovascular disease mortality would occur in the southern states if risk factors were reduced to levels in lower risk western states (Patel et al., 2015). Our state-specific IHD study supports these findings, and the need to reduce the prevalence of IHD risk behaviors.

In this study, the mortality rate disparity between AR and the US increased over time especially in the preMedicare age group. The importance of specific risk factors depended on race, sex, and age. Most of these increases in IHD death rates can be attributed to a higher prevalence of several risk factors in AR (Table 3). Taken together, these factors can probably explain the majority of the difference in IHD deaths between AR and the US (Figure 1, Table 4). However, it is problematic to account for correlations among risk factors when computing a cumulative contribution. This is primarily because BRFSS sample sizes were too small to estimate prevalence within cross-classifications of risk factors. The importance of specific risk factors depended on race, sex, and age, but hypertension was among the highest ranked in all demographic groups and smoking also ranked high among the factors. Because of their high ranks, we computed prevalence for their joint distribution. The ARCHES adjusted combination of hypertension and smoking contributed to the disparity of IHD mortality between AR and the US for all groups except black females (OBF, YBF), Table 3. Among black females in AR, hypertension prevalence is higher but smoking prevalence is lower than the US.

After adjusting AR mortality rates using the PAF (36.2) in Table 3, IHD mortality rates among black males in the Medicare group dropped significantly below US rates (Figure 1c and Table 4). Table 3 disregarded risk factors for which the AR prevalence was less than the US prevalence. AR prevalence estimates for diabetes and obesity were significantly lower in OBM, and this may contribute to the low adjusted estimate.

Differences between AR and the US socioeconomic factors and health insurance may play a significant role in these disparities (Alter et al., 2013; Baker et al., 2006; Fowler-Brown et al., 2007; McWilliams, Zaslavsky, Meara, \& Ayanian, 2004). In previous work, Balamurugan and coworkers estimated the relative risk of death from acute myocardial infarction (the major component of IHD deaths) in census block groups as a function of education (proportion of the block group population over 25 years old who did not graduate from high school) and poverty (proportion of the block group population living below the federal poverty level) (Balamurugan et al., 2016). Both of these covariates explained significant amounts of the differences in IHD mortality among Arkansas's block groups. This result implies that there are substantial differences in IHD mortality among block groups that are associated with socioeconomic measures.

While having no insurance explains some of the pre-mature IHD death among younger Arkansans compared to the US, it does not have an effect on the 65-84 age groups where essentially all have access to Medicare. A 10year prospective health study, the Health and Retirement Study (HRS), followed adults aged 55 to 64 and found those without insurance at the start of the study had a 35\% higher all-cause mortality rate than those who reported having private insurance (McWilliams et al., 2004). Some of this risk may be related to the lack of preventive care and interventions not available to the uninsured (Brooks et al., 2010). Investigators of the health insurance 
expansion under the Affordable Care Act (ACA) estimated that a $5.1 \%$ increase in treatment of hypertension among adults aged 25 to 64, would prevent 95,000 cardiovascular disease deaths in this group by 2050 (Li et al., 2015).

BRFSS allows us to address the prevalence differences between the US and AR in income, education, and health insurance status. However, a substantial part of the risk is presumed to be confounded by other risk factors. For example, both hypertension and smoking prevalence were correlated with measures of education and poverty (Luepker et al., 1993).

Because BRFSS is a self-reported survey, responses to questions about risk factors such as smoking and obesity may be biased by societal perceptions (Gebreab et al., 2015; Li et al., 2012; Nelson et al., 2003; Pierannunzi et al., 2013). For risk factors such as hypertension and diabetes, many individuals do not realize they have the condition. Underreporting results from other studies were incorporated to adjust for the underreporting of these chronic conditions (Centers for Disease Control and Prevention, 2018c; Zohoori et al., 2011). Our modeling also estimated the variation inherent in prevalence estimates, which allows us to include confidence intervals.

Limitations in the study include the relatively small samples among ages 45-64 and 65-84, which limits precision, and thus was especially problematic for the black population. The limited sample sizes in BRFSS also restricted our ability to examine interactions. For example, an interaction may occur between hypertension, smoking and cholesterol, but creating subsets to account for this effect modification reduces the sample further, resulting in less precise outcomes, which limit the power to evaluate effects. In addition, we would need estimates of the RR for the interaction subsets, which are largely unavailable.

The INTERHEART case-control study determined odds ratios among cases that were alive after their first MI event (Anand et al., 2008). We used these odds ratios as a risk measure of IHD death rather than MI incidence. Also, IHD includes heart diseases such as angina pectoris, other acute ischemic heart disease, and chronic ischemic heart disease besides acute and subsequent MI. There were also some differences in the way some of the risk factors are measured between BRFSS and the INTERHEART study, which may have led to inconsistent RR measures. Additional RR's for education, income, and health insurance were not available in the INTERHEART study. An excess RR for education and income were inferred from several studies, and the RR for health insurance was used from the Atherosclerosis Risk in Communities Study (Fowler-Brown et al., 2007; Lynch et al., 1996; Qureshi et al., 2003; Rasmussen et al., 2006; Tonne et al., 2005).

Our findings determine which program interventions would have the greatest benefit of reducing IHD rates. Targeting these interventions could support efforts of the CDC and CMS Million Hearts initiative to prevent 1 million cardiovascular disease deaths by 2022 (Centers for Disease Control and Prevention, 2018b).

\section{ACKNOWLEDGEMENTS}

No financial support was obtained for the work in this manuscript.

\section{REFERENCES}

Alter, D. A., Franklin, B., Ko, D. T., Austin, P. C., Lee, D. S., Oh, P. I., .. . Tu, J. V. (2013). Socioeconomic status, functional recovery, and long-term mortality among patients surviving acute myocardial infarction. PLoS One, 8, e65130. https:// doi.org/10.1371/journal.pone.0065130

American Heart Association. (2018). Understand Your Risks to Prevent a Heart Attack. Available at: http:/ /www.heart.org/en/health-topics/heart-attack/understand-your-risks-to-prevent-a-heart-attack

(Accessed 15 October 2018)

Anand, S. S., Islam, S., Rosengren, A., Franzosi, M. G., Steyn, K., Yusufali, A. H., . . Yusuf, S. (2008). Risk factors for myocardial infarction in women and men: insights from the INTERHEART study. European Heart Journal, 29. 932-940. https://doi.org/10.1093/eurheartj/ehn018

Baker, D. W., Sudano, J. J., Durazo-Arvizu, R., Feinglass, J., Witt, W. P. and Thompson, J. (2006). Health insurance coverage and the risk of decline in overall health and death among the near elderly, 1992-2002. Medical Care, 44, 277-282. https://doi.org/10.1097/01.mlr.0000199696.41480.45

Balamurugan, A., Delongchamp, R., Im, L., Bates, J. and Mehta, J. L. (2016). Neighborhood and Acute Myocardial Infarction Mortality as Related to the Driving Time to Percutaneous Coronary Intervention-Capable Hospital. Journal of the American Heart Association, 5, e002378. https:// doi.org/10.1161/JAHA.115.002378

Brooks, E. L., Preis, S. R., Hwang, S. J., Murabito, J. M., Benjamin, E. J., Kelly-Hayes, M., . . Levy, D. (2010). Health insurance and cardiovascular disease risk factors. The American Journal of Medicine, 123, 741-747. https://doi.org/10.1016/j.amjmed.2010.02.013 
Case, A. and Deaton, A. (2015). Rising morbidity and mortality in midlife among white non-Hispanic Americans in the 21st century. Proceedings of the National Academy of Sciences of the United States of America, 112, 15078-15083. https://doi.org/10.1073/pnas.1518393112

Centers for Disease Control and Prevention. (2013). Vital signs: avoidable deaths from heart disease, stroke, and hypertensive disease - United States, 2001-2010. MMWR.Morbidity and mortality weekly report, 62, 721-727.

Centers for Disease Control and Prevention. (2014). Underlying Cause of Death 1999-2011 on CDC WONDER Online Database, released 2014. Data are from the Multiple Cause of Death Files, 1999-2011, as compiled from data provided by the 57 vital statistics jurisdictions through the Vital Statistics Cooperative Program. Available at: http://wonder.cdc.gov/ucd-icd10.html

Centers for Disease Control and Prevention. (2015). Comparability of data: BRFSS 2011. Available at: http://www.cdc.gov/brfss/annual_data/2011/pdf/compare_11_20121212.pdf (Accessed 10 June 2015)

Centers for Disease Control and Prevention. (2018a). Behavioral Risk Factor Surveillance System (BRFSS) Prevalence Data (2010 and prior). Available at: https://healthdata.gov/dataset/behavioral-risk-factorsurveillance-system-brfss-prevalence-data-2010-and-prior (Accessed 15 October 2018)

Centers for Disease Control and Prevention. (2018b). Million Hearts. Available at: http://millionhearts.hhs.gov (Accessed 15 October 2018)

Centers for Disease Control and Prevention. (2018c). National Health and Nutrition Examination Survey Data. Hyattsville, MD: U.S. Department of Health and Human Services. Available at: https://wwwn.cdc.gov/nchs/nhanes/ContinuousNhanes/Default.aspx?BeginYear=2007 (Accessed 15 October 2018)

Cutler, D. M. and Meara, E. (2004). Changes in the Age Distribution of Mortality over the Twentieth Century. In D. A. Wise (Ed.), Perspectives on the Economics of Aging (pp. 333-365): University of Chicago Press. https:// doi.org/10.7208/chicago/9780226903286.003.0010

Efron, B. and Tibshirani, R. J. (1994). An Introduction to the Bootstrap: Chapman \& Hall.

Fowler-Brown, A., Corbie-Smith, G., Garrett, J. and Lurie, N. (2007). Risk of cardiovascular events and death-does insurance matter? Journal of general internal medicine, 22, 502-507. https://doi.org/10.1007/s11606-007-01272

Gebreab, S. Y., Davis, S. K., Symanzik, J., Mensah, G. A., Gibbons, G. H. and Diez-Roux, A. V. (2015). Geographic variations in cardiovascular health in the United States: contributions of state- and individual-level factors. Journal of the American Heart Association, 4. https:// doi.org/10.1161/JAHA.114.001673

Gillespie, C. D., Wigington, C. and Hong, Y. (2013). Coronary heart disease and stroke deaths - United States, 2009. Morbidity and mortality weekly report. Surveillance summaries (Washington, D.C.: 2002), 62 Suppl 3, 157-160.

Go, A. S., Mozaffarian, D., Roger, V. L., Benjamin, E. J., Berry, J. D., Blaha, M. J., ..., Stroke Statistics Subcommittee. (2014). Heart disease and stroke statistics--2014 update: a report from the American Heart Association. Circulation, 129, e28-e292. https://doi.org/10.1161/01.cir.0000441139.02102.80

Li, C., Balluz, L. S., Ford, E. S., Okoro, C. A., Zhao, G. and Pierannunzi, C. (2012). A comparison of prevalence estimates for selected health indicators and chronic diseases or conditions from the Behavioral Risk Factor Surveillance System, the National Health Interview Survey, and the National Health and Nutrition Examination Survey, 2007-2008. Preventive medicine, 54, 381-387. https://doi.org/10.1016/j.ypmed.2012.04.003

Li, S., Bruen, B. K., Lantz, P. M. and Mendez, D. (2015). Impact of Health Insurance Expansions on Nonelderly Adults with Hypertension. Preventing chronic disease, 12, E105. https://doi.org/10.5888/pcd12.150111

Luepker, R. V., Rosamond, W. D., Murphy, R., Sprafka, J. M., Folsom, A. R., McGovern, P. G. and Blackburn, H. (1993). Socioeconomic status and coronary heart disease risk factor trends. The Minnesota Heart Survey. Circulation, 88, 2172-2179. https:// doi.org/10.1161/01.CIR.88.5.2172

Lynch, J. W., Kaplan, G. A., Cohen, R. D., Tuomilehto, J. and Salonen, J. T. (1996). Do cardiovascular risk factors explain the relation between socioeconomic status, risk of all-cause mortality, cardiovascular mortality, and acute myocardial infarction? American journal of epidemiology, 144, 934-942. https://doi.org/10.1093/oxfordjournals.aje.a008863

McWilliams, J. M., Zaslavsky, A. M., Meara, E. and Ayanian, J. Z. (2004). Health insurance coverage and mortality among the near-elderly. Health affairs (Project Hope), 23: 223-233. https://doi.org/10.1377/hlthaff.23.4.223

Nelson, D. E., Powell-Griner, E., Town, M. and Kovar, M. G. (2003). A comparison of national estimates from the National Health Interview Survey and the Behavioral Risk Factor Surveillance System. American Journal of Public Health, 93, 1335-1341. https://doi.org/10.2105/AJPH.93.8.1335

Patel, S. A., Winkel, M., Ali, M. K., Narayan, K. M. and Mehta, N. K. (2015). Cardiovascular Mortality Associated With 5 Leading Risk Factors: National and State Preventable Fractions Estimated From Survey Data. Annals of Internal Medicine. https:// doi.org/10.7326/M14-1753 
Pierannunzi, C., Hu, S. S. and Balluz, L. (2013). A systematic review of publications assessing reliability and validity of the Behavioral Risk Factor Surveillance System (BRFSS), 2004-2011. BMC medical research methodology, 13, 492288-2213-2249. https://doi.org/10.1186/1471-2288-13-49

Qureshi, A. I., Suri, M. F. K., Saad, M. and Hopkins, L. N. (2003). Educational attainment and risk of stroke and myocardial infarction. Medical Science Monitor, 9, 466-473.

Rasmussen, J. N., Rasmussen, S., Gislason, G. H., Buch, P., Abildstrom, S. Z., Køber, L., .., Madsen, M. (2006). Mortality after acute myocardial infarction according to income and education. Journal of Epidemiology \& Community Health, 60, 351-356. https:// doi.org/10.1136/jech.200X.040972

Tonne, C., Schwartz, J., Mittleman, M., Melly, S., Suh, H. and Goldberg, R. (2005). Long-term survival after acute myocardial infarction is lower in more deprived neighborhoods. Circulation, 111, 3063-3070. https://doi.org/10.1161/CIRCULATIONAHA.104.496174

US Department of Health \& Human Services. (2015). Key features of the Affordable Care Act by year. Available at: http://www.hhs.gov/healthcare/facts-and-features/key-features-of-aca-by-year/index.html (Accessed 8 July 2015)

Zohoori, N., Pulley, L., Jones, C., Senner, J., Shoob, H. and Merritt, R. K. (2011). Conducting a statewide health examination survey: the Arkansas Cardiovascular Health Examination Survey (ARCHES). Preventing chronic disease, 8, A67. 